
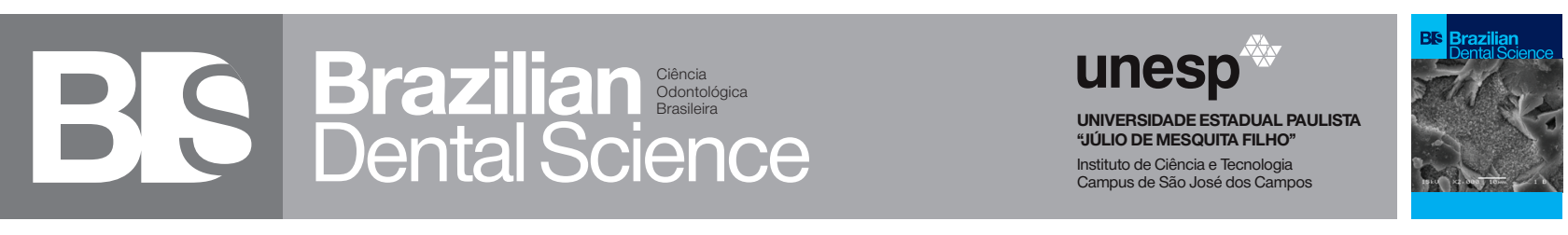

\title{
Periodontal disease defects and mandibular cortical index in lupus patients
}

\author{
Defeitos ósseos periodontais e índice da cortical mandibular em pacientes com lupus
}

Vagner B. da SILVA ${ }^{1}$, Lucas MORITA ${ }^{1}$, Luciana MUNHOZ ${ }^{1}$, Silvia V. LOURENÇO ${ }^{1}$, Emiko S. ARITA ${ }^{1}$

1 - Department of Stomatology, School of Dentistry, University of São Paulo - São Paulo - SP - Brazil.

\begin{abstract}
Introduction: Systemic lupus erythematosus is an autoimmune disease that affects multiple organs. It is well known that lupus patients have higher risk of osteoporosis, but if the disease affects mandibular cortical bone and alveolar bone is not fully established. Objective: The objective of this study was to evaluate periodontal disease defects and mandibular osteoporotic alterations in patients with lupus as compared to healthy patients using panoramic radiographs. Material and Methods: The panoramic radiographs of 72 patients with lupus and 360 healthy patients were evaluated for the presence of bone loss secondary to periodontal disease, classified as horizontal and vertical bone loss. We also assessed mandibular osteoporotic alterations by using the mandibular cortical index. Logistic regression analysis was applied to estimate the risk of mandibular osteoporotic alterations as well as horizontal and vertical bone loss in patients with lupus as compared to healthy patients. Results: There were no statistically significant differences between groups in the presence of horizontal bone defects and mandibular cortical indexes. However, patients with lupus demonstrated that patients with lupus were 2.17 more likely to present vertical bone loss than healthy patients. Conclusions: Patients with lupus might have higher risk of vertical bone loss than healthy patients due to pathophysiology of their disease. Further larger prospective studies should be performed to confirm our findings.
\end{abstract}

\section{KEYWORDS}

Panoramic radiograph; Periodontal disease; Osteoporosis, Systemic Lupus Erythematosus; Cutaneous Lupus Erythematosus; Bone mineral density.

\section{RESUMO}

Introdução: Os lúpus eritematoso sistêmico é uma doença autoimune que afeta múltiplos órgãos. Pacientes com lúpus têm maior risco de osteoporose, mas é necessário elucidar-se como a doença afeta o esqueleto maxilo-mandibular. Objetivo: O objetivo deste estudo foi avaliar defeitos ósseos por doença periodontal e alterações osteoporóticas mandibulares em pacientes com lúpus, em comparação com pacientes saudáveis, utilizando-se radiografias panorâmicas. Material e Métodos: As radiografias panorâmicas de 72 pacientes com lúpus e 360 pacientes saudáveis foram avaliadas quanto à presença de defeitos ósseos verticais e horizontais por doença periodontal. Foram também avaliadas as alterações osteoporóticas da mandíbula por meio do índice da cortical mandibular. A regressão logística foi aplicada para estimar o risco de alterações osteoporóticas mandibulares, bem como a perda óssea horizontal e vertical em pacientes com lúpus, em comparação com pacientes saudáveis. Resultados: Não houveram diferenças estatisticamente significantes entre os grupos no tocante à presença de defeitos ósseos horizontais quanto à redução da densidade mineral óssea aferida por meio do índice da cortical mandibular. No entanto, pacientes com lúpus apresentaram 2,17 mais risco à perda óssea vertical do que pacientes saudáveis. Conclusões: Pacientes com lúpus podem ter maior risco de apresentar defeito ósseo vertical do que pacientes saudáveis devido à fisiopatologia de sua doença. Novos estudos prospectivos devem ser realizados para confirmar estes achados.

\section{PALAVRAS-CHAVE}

Radiografia panorâmica; Doença periodontal; osteoporose; Lupus sistêmico eritematoso; Lupus cutâneo eritematoso; Densidade mineral óssea. 


\section{INTRODUCTION}

ystemic Lupus Erythematosus (SLE) is an - autoimmune disease with heterogeneous features that may affect multiple organs and presents with a wide range of clinical and laboratory abnormalities [1,2]. SLE frequently leads to permanent damage and, although it can have periods of remission, there is no cure. [3] SLE has distinct subdivisions according to the degree of impairment or organ involvement. One of these subdivisions is Cutaneous Lupus Erythematosus (CLE), which can occur independently or with SLE [4].

The disease affects 30-50/10,000 individuals worldwide [5] and over $90 \%$ of patients are women [3]. Life expectancy has improved in patients with lupus patients due to pharmaceutical advances. However, bone loss associated with low-impact fragility fractures and morbidity has considerably increased in lupus patients over time.[3] Osteoporosis occurs in $10-68 \%$ of patients with particularly SLE [6].

Osteoporosis is an osteometabolic disease that leads to low bone mineral density (BMD) [7] and, similarly to lupus, affects mostly women. The diagnosis of osteoporosis is obtained by dual energy x-ray absorptiometry (DEXA), which is a reliable and accurate test. However, a DEXA scan is expensive and not accessible in developing countries [8]. Hence, a number of screening tools have been created to detect patients at increased risk of osteoporosis, such as radiomorphometric indexes in panoramic radiographs.

A panoramic radiograph is a radiographic examination frequently used as the initial examination in dental clinics [9]. With panoramic radiographs, is it possible to evaluate the mandibular cortical index (MCI). The MCI assesses the morphological appearance of the cortical bone at the mandibular endosteal margin [10], and it is a useful screening tool to evaluate risk of osteoporosis [8,9,11-14].

Panoramic radiographs are also a valuable tool to screen for periodontal disease. $[15,16]$ Although intraoral radiographs are the most ideal for the evaluation of periodontal tissue, particularly bone involvement [17], panoramic radiographs present advantages over intraoral radiographs, such as low cost, convenience and reduced radiation exposure [17-19]. Furthermore, digital panoramic radiographs improve the evaluation of periodontal bone tissue since they can provide better visualization of structures with tools such as the ability to enlarge or contrast and brightness changes [20,21].

Thus, the objective of this study was to evaluate periodontal disease defects (horizontal and vertical bone loss) and mandibular osteoporotic alterations (using MCI) in patients with lupus (SLE and CLE) as compared to healthy patients of the same age and gender, using panoramic radiographs.

\section{MATERIAL AND METHODS}

Study participants and inclusion and exclusion criteria

This retrospective study was conducted with 72 patients who had a confirmed diagnosis of lupus (from the Dermatology Department, Ambulatory of Collagenosis and Stomatology, Hospital das Clínicas de São Paulo, Brazil) and 360 healthy patients (from São Paulo University Dentistry School, Brazil) who underwent panoramic radiographic examinations for dental treatment. Patients with lupus were diagnosed with SLE and/or CLE. Approval was obtained from the Ethics Committee at São Paulo University Dentistry and Medicine School (number 2.701.761). The guidelines of Helsinki were followed in this investigation. 
Panoramic radiographic examinations with technical failures were excluded. The healthy patients were selected randomly using the following criteria: for each lupus patient, five non-lupus patients with the same gender and age were selected.

MCI assessments were performed independently by three experienced radiologists two weeks apart to avoid memory bias. Intraobserver reliability was assessed between measurements. The radiologists assessed the appearance of the cortical bone at the mandibular endosteal margin on both sides of the mandible, between the mental foramen to the posterior limit of the angle of the mandible, using the Klemmeti classification [12]. This classification is as follows: $\mathrm{C} 1=$ normal, seen as a sharp and marked continuous endosteal margin; C2 = moderately eroded, seen as evidence of lacunar resorption and C3 $=$ severely eroded, seen as obvious reduction of mandibular bone mineral density.

The presence of periodontal bone loss was classified as "horizontal" or "vertical" according to the appearance of alveolar bone of the remaining teeth and considering six distinct areas for descriptive purposes: anterior inferior, anterior superior, posterior superior left, posterior superior right, posterior inferior left and posterior inferior right. Furthermore, the number of missing teeth was also evaluated.

A control group of 360 healthy individuals was created using panoramic radiographs performed for dental treatment. The control group was matched with the patients with lupus for age, sex and number of missing teeth (we accepted a difference of no more than + two missing teeth or years in age for each patient selected). For each patient with lupus, five matched healthy individuals with panoramic radiographs were searched for individually in the Dentistry University database.

\section{Statistical Analysis}

Normality of the variables was assessed using the Shapiro-Wilk test. Logistic regression was used to assess the risk of low MCI in panoramic radiographs (represented by MCI C2 and C3 classifications) and presence of periodontal disease (horizontal and vertical bone defects in panoramic radiographs) in patients with and without lupus. Risk estimates were reported as odds ratios (OR) with 95\% confidence intervals (CIs).

Intra- and inter-observer agreement was assessed using the Kappa test for MCI and presence of periodontal disease defects.

All statistical analyses were performed using the IBM SPSS Statistics 24 software (SPSS, Inc., Chicago, IL, USA).

\section{RESULTS}

As the variables were not normal $(\mathrm{p}=$ 0.000 ), data are presented as median values and interquartile ranges when applicable.

\section{Descriptive data}

Table 1 depicts the number and age of patients, as well as their treatment and systemic comorbidities (number of patients using medication that affects bone metabolism, such as corticosteroids; number of patients with systemic disease, such as diabetes), as well as median number of missing teeth, number of patients with low MCI (classified as MCI 2 and 3) and patients with periodontal disease (vertical or horizontal bone loss detected in panoramic radiographs). Table 2 shows descriptive data regarding the number of remaining teeth and periodontal bone loss according to the aforementioned classification (anterior inferior area, anterior superior area, posterior superior left area, posterior superior right area, posterior inferior left area, posterior inferior right area). 
Table 1 - Descriptive data of study patients. Number of patients, median age of the patients, number of patients using medication that affects bone metabolism, number of patients with other systemic disease, median number of missing teeth, number of patients with mandibular cortical index 2 or 3 , number of patients with periodontal disease (horizontal and/or vertical bone defects detected in panoramic radiographs)

\begin{tabular}{|c|c|c|c|c|c|c|c|}
\hline & $\mathbf{n}$ & Age & $\begin{array}{l}\text { Medicationthataffects } \\
\text { bonemetabolism }\end{array}$ & Comorbidities & Missingteeth & MCI2and3 & Periodontal disease \\
\hline SLE & 7 & 36(IR69) & 7 & 29 & $8(\mid \mathrm{R} 12)$ & 1 & 7 \\
\hline CLE & 59 & 64(IR9) & 31 & 3 & $27(\mathbb{R} 8)$ & 24 & 42 \\
\hline SLE + CLE & 6 & 46(IR39) & 6 & 10 & 11(IR22) & 4 & 5 \\
\hline All lupus patients & 72 & $46(\mathbb{R} 27)$ & 44 & 42 & 16 (IR19) & 29 & 54 \\
\hline Control group & 360 & 46(IR20) & 0 & 0 & 16(IR17) & 74 & 203 \\
\hline
\end{tabular}

Abbreviations: SLE: patients with Systemic Erythematous Lupus, CLE: patients with Cutaneous Lupus Erythematous, SLEÜCLE: Patients with systemic and cutaneous lupus, MCl: mandibular cortical index, IR: interquartile range.

Table 2 - Descriptive data of periodontal bone loss in the sample studied reported as the numbera of patients with a regional bone loss

\begin{tabular}{|ccccc|}
\hline \multicolumn{2}{c}{ Area } & \multicolumn{2}{c}{ Lupuspatients } & \multicolumn{2}{c|}{ Healthypatients } \\
& Horizontalboneloss & Vertical boneloss & Horizontalboneloss & Verticalboneloss \\
\hline Anterior inferior & 45 & 2 & 136 & 5 \\
\hline Anterior superior & 26 & 4 & 86 & 10 \\
\hline Posterior superior left & 16 & 9 & 101 & 7 \\
\hline Posterior superior right & 19 & 4 & 93 & 1 \\
\hline Posterior inferior right & 20 & 5 & 105 & 8 \\
\hline Posterior inferior left & 21 & 6 & 114 & 5 \\
\hline
\end{tabular}

${ }^{a}$ The same patient can have more than one alteration. Patients without any detectable bone loss were not included.

\section{Statistical assessment results}

The Kappa test for MCI and periodontal disease showed significant values of 0.88 (p $=0.001)$ and $0.91(\mathrm{p}=0.000)$, respectively. No statistically significant differences were observed after logistic regression for horizontal defects and MCI, seen in Table 3. However, patients with lupus demonstrated 2.17 more chances to present vertical bone loss than healthy patients.
Table 3 - Logistic regression results

\begin{tabular}{|c|c|c|}
\hline Variables & OR $(95 \% \mathrm{Cl})$ & $\mathbf{p}^{\star}$ \\
\hline \multicolumn{3}{|c|}{ Horizontal bone loss } \\
\hline Absence & 1 & \\
\hline Presence & $0.79(0.36-1.71)$ & 0.55 \\
\hline \multicolumn{3}{|c|}{ Vertical bone loss } \\
\hline Absence & 1 & \\
\hline Presence & $2.17(0.90-5.25)$ & 0.08 \\
\hline \multicolumn{3}{|l|}{ MCI } \\
\hline Normal & 1 & \\
\hline Low & $2.17(0.90-5.25)$ & 0.08 \\
\hline
\end{tabular}

Abbreviations: OR: odds ratio; Cl: confidence interval 


\section{DISCUSSION}

In the present study, we found that patients with lupus do not have a higher risk of horizontal bone loss or low MCI (MCI classifications 2 and 3) when compared to healthy patients. However, patients with lupus presented 2.17 higher risk of vertical bone loss than healthy patients $\mathrm{p}=0.08$ ).

Lupus is a chronic inflammatory disease with multiple osteometabolic effects that lead to increased osteoclastic activity and decreased osteoblastic activity. [3] Furthermore, vitamin D deficiency is more prevalent in patients with lupus [22], who usually avoid sun exposure, as ultraviolet light is a trigger to disease flare [23]. The role of vitamin D in bone metabolism is well known, and vitamin D accelerates bone metabolism and prevents osteoporotic fractures. [24] Additionally, chronic kidney disease, which is frequent in lupus patients, can lead to altered calcium and vitamin D homeostasis [25].

Although it is well established that lupus may lead to dysfunction of multiple organs [26], few studies have investigated association with periodontal disease $[26,27]$ and none have examined mandibular bone mineral density using MCI assessment. To our knowledge, this is the first investigation using the mandibular cortical index in this group of patients.

Osteoporosis is an common complication of lupus, [28] and mandibular bone can reflect systemic osteoporotic alterations [29-31], which can be analyzed by radiomorphometric indexes, such as MCI in panoramic radiographs. Moreover, MCI has been already significantly inversely correlated with DEXA results in several studies $[11,12,14]$. In this investigation, surprisingly, patients with lupus did not show a higher risk of low MCI. This finding may be related to the young median age of the patients ( 46 years old) or to the small sample size. No direct comparisons between our study findings and other investigations were performed, as this is the first study related to lupus using this methodology.

Previous studies have shown that patients with lupus have a higher risk $[26,32]$ or prevalence [27] of periodontal disease and have suggested that periodontal disease seems to develop earlier [33]. However, other studies using clinical examination had contradictory results and concluded that rates of periodontal disease are similar in patients with lupus and healthy patients [32].

There are no prior studies that specifically associate vertical bone loss with lupus, which the major finding of our study. Alveolar bone loss due to periodontal disease is cumulative, and its measurement is essential to determine the severity of the diagnosis [34]. Vertical alveolar bone loss is often associated with aggressive periodontal disease, in which bone loss can be on one, two, three or all sides of the tooth [35].

Patients with lupus are more likely to have osteoporosis due to drugs, such as corticosteroids. Corticosteroids, commonly used in treatment of SLE, play a role in increasing osteoporosis risk, since this type of medication affects bone metabolism, changing the balance between osteoclasts and osteoblasts to favor bone loss. [36] A possible explanation for increased vertical bone loss in patients with lupus may be associated with lupus treatment, although not all patients in our sample were on corticosteroids.

Some studies of patients with lupus showed that these patients have more periodontal complications [26,27,32]. Periodontal complications are associated with higher level of pro-inflammatory cytokines and a heightened count of Actinobacillus actinomycetemcomitans. As lupus patients has elevated levels of pro-inflammatory cytokines 
[37], is expected that they have higher risk to develop periodontal disease. The significant increase in periodontitis in patients with lupus might be related to their susceptibility to periodontal disease by its inherent host response due to the disease itself $[38,39]$.

The limitations of the present investigation are the small sample size and the retrospective nature of the study. Prior studies examining periodontal disease in patients with lupus reported conflicting results [40-42]. High variance in the clinical research criteria for severity of periodontal disease might play a role in the results.

\section{CONCLUSIONS}

In conclusion, the role of corticosteroids in patients with lupus and periodontal disease is still unclear, and MCI assessment did not show any statistically significant difference in lupus patients as compared to healthy controls. Patients with lupus might have higher risk of vertical bone loss than healthy patients due to the pathophysiology of the disease, and perhaps lupus may have a synergistic effect, worsening periodontal disease and making it more aggressive. In the future, larger prospective studies should be performed to confirm our findings.

\section{REFERENCES}

1. VerweijCL, Vosslamber S. Combining DNA-microarray data in systemic lupus erythematosus. Genome Med. 2011 May;3(5):30. doi: 10.1186/gm246

2. Benigni A, Cassis P, Remuzzi G. Angiotensin II revisited: new roles in inflammation, immunology and aging. EMBO Mol Med. 2010 Jul;:2(7):247-57.

3. Edens C, Robinson AB. Systemic lupus erythematosus, bone health, and osteoporosis. Curr Opin Endocrinol Diabetes Obes. 2015 Dec;22(6):422-31. doi: 10.1097/MED.0000000000000197.

4. Murphy B,McCourtC, O'Kane D. Risk factors for development of systemic lupus erythematosus in patients with cutaneous lupus: a retrospective review. Clin Exp Dermatol. 2019 Mar;44(20):e26-7. doi: 10.1111/ced.13802.

5. Danchenko N, Satia JA, Anthony MS. Epidemiology of systemic lupus erythematosus: a comparison of worldwide disease burden. Lupus. 2006;15(5):308-18.
6. Yeap SS, Othman AZ,Zain AA, Chan SP.Vitamin D levels: its relationship to bone mineral density response and disease activity in premenopausal Malaysian systemic lupus erythematosus patients on corticosteroids. Int J Rheum Dis. 2012Feb;15(1):17-24. do: 10.1111/j.1756-185X.2011.01653.X.

7. Diniz-Freitas M,Fernández-Montenegro P,Fernández-Feijoo J,Limeres-Posse J,González-Mosquera A, Vázquez-GarcíaE, Diz-Dios P.Mandibular cortical indices on cone-beam computed tomography images in osteoporotic women on treatment with oral bisphosphonates. Gerodontology. 2016 Jun;33(2):15560. doi: 10.1111/ger.12121.

8. Nakamoto T, Taguchi A, Ohtsuka M, Suei Y,Fujita M, Tanimoto K, etal. Dental panoramic radiograph as a tool to detect postmenopausal women with low bone mineral density: untrained general dental practitioners' diagnostic performance. 0steoporos Int. 2003 Aug;14(8):659-64. doi:10.1007/s00198003-1419-y

9. Taguchi A. Triage screening for osteoporosis in dental clinics using panoramic radiographs. Oral Dis. 2010 May;16(4):316-27. doi: 10.111//.16010825.2009.01615.x.

10. Kolte RA, Kolte AP,Potey AM. Risk assessment of osteoporosis in pre-and postmenopausal periodontally healthy and chronic periodontitis women with digital panoramic radiographs. J Indian Soc Periodontol. 2017 NovDec;21(3):461-465. doi:10.4103/isp.jisp 23817

11. Munhoz L, Aoki EM, Cortes ARG, de Freitas CF,AritaES. Osteoporotic alterations in a group of different ethnicity Brazilian postmenopausal women: An observational study. Gerodontology.2018 Jun;35(2):101-9. doi:10.1111/ ger.12322.

12. KlemettiE, Kolmakov S, Kröger H.Pantomography in assessment of the osteoporosis risk group. Scand J Dent Res. 1994 Feb;102(1):68-72.

13. Hastar E, Yilmaz HH, Orhan H. Evaluation of mental index, mandibular cortical index and panoramic mandibular index on dental panoramic radiographs in the elderly. Eur JDent. 2011 Jan;5(1):60-67.

14. MunhozL, Cortes AR, Arita ES. Assessment of osteoporotic alterations in type 2 diabetes: a retrospective study. Dentomaxillofac Radiol. 2017 Aug; 46(6):20160414. doi:10.1259/dmfr.20160414.

15. Bollen AM, Taguchi A, Hujoel PP, Hollender LG. Case-control study on selfreported osteoporotic fractures and mandibular cortical bone. Oral Surg Oral Med Oral Pathol Oral Radiol Endod. 2000 0ct;90(4):518-24. doi: 10.1067/ moe.2000.107802

16. DrozdzowskaB, Pluskiewicz W, Tarnawska B. Panoramic-based mandibular indices in relation to mandibular bone mineral density and skeletal status assessed by dual energy $\mathrm{X}$-ray absorptiometry and quantitative ultrasound. Dentomaxillofac Radiol.2002 Nov;31(6):361-7.

17. Pepelassi EA, Diamanti-Kipioti A. Selection of the mostaccurate method of conventional radiography for the assessment of periodontal osseous destruction. J Clin Periodontol. 1997 Aug;24(8):557-67.

18. Kim TS, ObstC, Zehaczek S, Geenen C. Detection of bone loss with different X-ray techniques in periodontal patients. J Periodontol. 2008 Jul;:79(7):1141-9. doi: 10.1902/jop.2008.070578.

19. Tugnait A, Carmichael F.Use of radiographs in the diagnosis of periodontal disease.DentUpdate. 2005 Nov;32:536-8541-2. doi:10.12968/ denu.2005.32.9.536

20. CorbetEF,Ho DK, Lai SM. Radiographs in periodontal disease diagnosis and management. Aust Dent J.2009 Sep;54(1):S27-43. doi: 10.1111/.j.18347819.2009.01141.x

21. Ridao-SacieC,Segura-Egea JJ,Fernández-Palacín A,Bullón-Fernández P,Ríos-Santos JV. Radiological assessment of periapical status using the periapical index: comparison of periapical radiography and digital 
panoramic radiography. Int Endod J. 2007;40(6):433-40. doi: 10.1111//.13652591.2007.01233.x

22. Petri M, Bello KJ,Fang H, Magder LS. Vitamin D in systemic lupus erythematosus: modest association with disease activity and the urine protein-to-creatinine ratio. Arthritis Rheum. 2013;65(7):1865-71. doi:10.1002/ art37953.

23. Shoenfeld N, Amital H, Shoenfeld $Y$. The effect of melanism and vitamin D synthesis on the incidence of autoimmune disease. Nat Clin Pract Rheumatol. 2009 Feb;5(2):99-105.

24. Bouillon R, Marcocci C, Carmeliet G, Bikle D, White JH, Dawson-Hughes B, Lips P,Munns CF, Lazaretti-Castro M, Giustina A, Bilezikian J. Skeletal and extraskeletal actions of vitamin D:Current evidence and outstanding questions. Endocr Rev. 20180ct;00126

25. Arya V,Bhambri R, Godbole MM, Mithal A. Vitamin D status and its relationship with bone mineral density in healthy Asian Indians. Osteoporos Int. 2004 Jan; ;5(1):56-61.

26. Zhang Q, Zhang X, Feng G, Fu T, Yin R, Zhang L, Feng X, LiL, GuZ Z Periodontal disease in Chinese patients with systemic lupus erythematosus. Rheumatol Int. 2017 Aug;37(8):1373-9.

27. Hammoudeh M, Al-Momani A, SarakbiH, ChandraP,Hammoudeh S. Oral Manifestations of Systemic Lupus Erythematosus Patients in Qatar: A Pilot Study. Int JRheumatol. 2018 Apr;2018:6052326.

28. Adachi JD, Lau A. Systemic lupus erythematosus, osteoporosis, and fractures JRheumatol. 2014 Oct;441(1):1913-1915.

29. Dutra V, Devlin H, Susin C, Yang J, Horner K, Fernandes AR. Mandibular morphological changes in low bone mass edentulous females: evaluation of panoramic radiographs. Oral Surg Oral Med Oral Pathol Oral Radiol Endod. 2006 Nov;102(5):663-668.

30. Taguchi A, Ohtsuka M, Tsuda M, Nakamoto T, Kodama I, Inagaki K, Noguchi T, Kudo Y, Suei Y, Tanimoto K. Risk of vertebral osteoporosis in post-menopausal women with alterations of the mandible. Dentomaxillofac Radiol. 2007 Mar;36(3):143-148

31. White SC, Atchison KA, Gornbein JA, Nattiv A, Paganini-Hill A, Service SK, Yoon DC. Change in mandibular trabecular pattern and hip fracture rate in elderly women. Dentomaxillofac Radiol. 2005 May;34(3):168-174.
32 Al-Mutairi KD, Al-Zahrani MS, Bahlas SM, Kayal RA, Zawawi KH. Periodontal findings in systemic lupus erythematosus patients and healthy controls. Saudi Med J.2015Apr;36(4):463-468.

33. Calderaro DC, Ferreira GA, Corrêa JD, Mendonça SM, Silva TA, Costa F0, Lúcio Teixeira A. Is chronic periodontitis premature in systemic lupus erythematosus patients? Clin Rheumatol. 2017 Mar;36(3):713-718.

34. Teeuw WJ, Coelho L, Silva A, van der Palen CJ, Lessmann FG, van der Velden U, Loos BG. Validation of a dental image analyzer tool to measure alveolar bone loss in periodontitis patients. J Periodontal Res. 2009 Feb;44(1):94-102.

35. Wang CH, Liu HW, Ou KL, Teng NC, Yu JJ, Huang HM. Natural frequency analysis of tooth stability under various simulated types and degrees of alveolar vertical bone loss. Proc Inst MechEng H. 2008 Aug;222(6):983-9.

36. MitraR. Adverse effects of corticosteroids on bone metabolism: a review. PMR R. 2011May;3):466-71.

37. Esfandiari E, Mclnnes IB, Lindop G, Huang FP,Field M, Komai-Koma M, Wei X, Liew FY. A proinflammatory role of IL-18 in the development of spontaneous autoimmune disease. J Immunol. 2001 Nov;167(9):5338-47.

38. Sete MRC,Carlos JC, Lira-Junior R, Boström EA, Sztajnbok FR, Figueredo CM. Clinical, immunological and microbial gingival profile of juvenile systemic lupus erythematosus patients. Lupus 2019;28:189-198.

39. Rutter-Locher Z, Smith TO, Giles I, SofatN. Association between Systemic Lupus Erythematosus and Periodontitis: A Systematic Review and Metaanalysis. Front Immunol. 2017 Fev;8(2):1295.

40. Fabbri C, Fuller R, BonfáE, Guedes LK, D'Alleva PS, Borba EF.Periodontitis treatment improves systemic lupus erythematosus response to immunosuppressive therapy. Clin Rheumatol. 2014;33(4):505-9.

41. Kobayashi T, Ito S, Yasuda K, Kuroda T, Yamamoto K, Sugita N, Tai H, Narita I, Gejyo F, Yoshie H. The combined genotypes of stimulatory and inhibitory Fc gamma receptors associated with systemic lupus erythematosus and periodontitis in Japanese adults. J Periodontol. 2007 Mar;78(3):467-74.

42. Calderaro DC, Ferreira GA, de Mendonça SM, Corrêa JD, Santos FX, Sanção JG, da Silva TA, Teixeira AL. Is there an association between systemic lupus erythematosus and periodontal disease? Rev Bras Reumatol Engl Ed. 2016 May-Jun;56(3):280-4.

\section{Luciana Munhoz}

\section{(Corresponding address)}

Department of Stomatology, School of Dentistry, University of São Paulo, 2227

Lineu Prestes Avenue. Zip Code: 05508-000 São Paulo, SP, Brazil.

E-mail address: dra.lucimunhoz@usp.br

Date submitted: 2019 Jun 18

Accept submission: 2019 Aug 26 